\title{
ARTICLE
}

\section{Genetic refinement of the hereditary neuralgic amyotrophy (HNA) locus at chromosome 17q25}

\author{
Jan Meuleman ${ }^{1}$, Gregor Kuhlenbäumer ${ }^{1,2}$, Anja Schirmacher ${ }^{2}$, Manfred Wehnert ${ }^{3}$, \\ Peter De Jonghe ${ }^{1,4}$, Els De Vriendt ${ }^{1}$, Peter Young ${ }^{2}$, Eila Airaksinen ${ }^{5}$, \\ Adolfo Pou-Serradell ${ }^{6}$, José-Maria Prats ${ }^{7}$, Bernd Ringelstein ${ }^{2}$, Florian Stögbauer ${ }^{2}$, \\ Christine Van Broeckhoven ${ }^{1}$ and Vincent Timmerman ${ }^{1}$
}

${ }^{1}$ Department of Molecular Genetics, Flanders Interuniversity Institute for Biotechnology, Born-Bunge Foundation, Department of Biochemistry, University of Antwerp, Antwerpen, Belgium

${ }^{2}$ Department of Neurology, University Hospital Münster, Münster, Germany

${ }^{3}$ Institute for Human Genetics, University of Greifswald, Greifswald, Germany

${ }^{4}$ Division of Neurology, University Hospital Antwerp, Antwerpen, Belgium

${ }^{5}$ Department of Pediatrics, Kuopio University Hospital, Kuopio, Finland

${ }^{6}$ Department of Neurology, University of Barcelona, Barcelona, Spain

${ }^{7}$ Department of Pediatrics, Hospital of Cruces, Barakaldo, Spain

\begin{abstract}
Hereditary neuralgic amyotrophy (HNA) is an autosomal dominant, recurrent focal neuropathy. HNA is characterised by episodes of painful brachial plexus neuropathy with muscle weakness and atrophy, as well as sensory disturbances. Single episodes are commonly preceded by non-specific infections, immunisations or parturition. Mild dysmorphic features and short stature are present in some HNA families, but absolute co-segregation with HNA has not been described. To refine the previously described HNA locus on chromosome 17q25, we performed a genetic linkage study in five HNA families with different geographic origins. Significant linkage was obtained with chromosome 17q24-q25 short tandem repeat (STR) markers in three HNA families and suggestive linkage was found in the other two HNA families. Analysis of the informative recombinations in affected individuals allowed us to reduce the HNA linkage interval to a candidate region of $3.5 \mathrm{cM}$.
\end{abstract}

Keywords: hereditary neuralgic amyotrophy; molecular genetics; linkage analysis

\section{Introduction}

Hereditary Neuralgic Amyotrophy (HNA) (OMIM No 162100) is an autosomal dominant, recurrent focal neuropathy, also called familial brachial plexus neurop-

Correspondence: Dr Vincent Timmerman PhD, Laboratory of Molecular Genetics, Peripheral Neuropathy Group, University of Antwerp (UIA), Department of Biochemistry, Universiteitsplein 1, B-2610 Antwerpen, Belgium. Tel: + 323 8202321; Fax: + $32 \quad 3$ 8202541; E-mail: timmerm@uia.ua.ac.be

Received 31 March 1999; revised 14 June 1999; accepted 29 June 1999 athy. ${ }^{1,2}$ The clinical hallmarks are episodes of painful brachial plexus neuropathy with muscle weakness and atrophy. Sensory disturbances can occur, but the motor weakness is usually more prominent. Muscle weakness is preceded by severe pain in the affected arm. Recurrent episodes can affect the same, as well as the opposite arm. Both arms can be involved simultaneously. Cranial nerves and the lumbosacral plexus are rarely affected. Recovery is usually complete, although a residual deficit may occur, especially after recurrent episodes. Age at onset of HNA is most commonly in the second decade of life, although children in the first 
decade can be affected. Single episodes are commonly triggered by non-specific infections, ${ }^{3}$ immunisations ${ }^{4}$ or parturition. ${ }^{5,6}$ Several dysmorphic features, such as hypotelorism, epicantal folds and cleft palate, as well as short stature, are present in some HNA families. ${ }^{7-9}$

Sporadic brachial plexus neuropathy, or ParsonageTurner syndrome, ${ }^{10}$ is much more common than HNA. ${ }^{11}$ Clinically, Parsonage-Turner syndrome does not differ substantially from HNA. ${ }^{12}$ Distinguishing features between HNA and Parsonage-Turner syndrome are family history, presentation in childhood and increased rate of recurrence in HNA.,12

A locus for HNA was assigned to a $4 \mathrm{cM}$ interval at chromosome $17 \mathrm{q} 24-\mathrm{q} 25$ by Pellegrino et al ${ }^{13,14}$ in two American families (Figure 1). We confirmed linkage to chromosome $17 \mathrm{q} 24-\mathrm{q} 25$ in a small German family ${ }^{15}$ and in a large Turkish family ${ }^{16}$ and defined a $16 \mathrm{cM}$ candidate region for HNA between the short tandem repeat (STR) markers D17S1301 (centromeric) and D17S784 (telomeric) (Figure 1). ${ }^{16}$ Here we performed a linkage study in five HNA families from different geographical areas. Our results demonstrated co-segregation of HNA with chromosome 17q25 STR

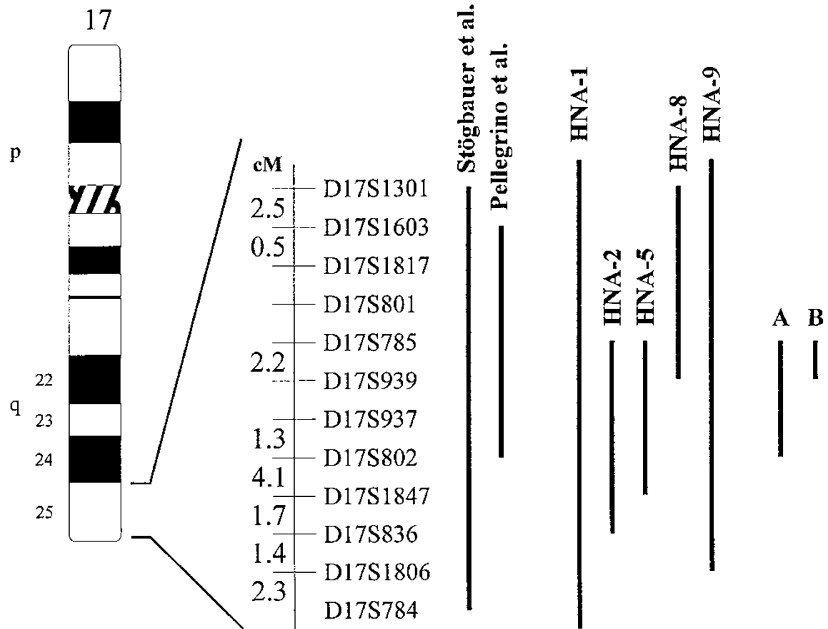

Figure 1 Ideogram of chromosome 17 showing the location of the HNA locus relative to the genetic map of STR markers. Genetic distances between the STRs are in $c M .{ }^{17}$ The stepwise reduction of the HNA candidate region is indicated. The $16 \mathrm{cM}$ region between D17S1301 and D17S784 is previously reported by Stögbauer et al, the $4 c M$ region between D17S1603 and D17S802, previously reported by Pellegrino et al. No informative recombinations were found in $H N A-1$; the refinement to a $9.3 \mathrm{cM}$ region in $H N A-2$; the $7.6 \mathrm{cM}$ region defined in $H N A-5$; the $5.2 \mathrm{cM}$ region based on an informative recombination in an unaffected individual in HNA-8 and the region defined in HNA-9. Region A: the $3.5 \mathrm{cM}$ overlap between the region defined by Pellegrino et al and the results of the present study. Region B: the 2.2 cM overlap between the regions defined in HNA-2, HNA-5 and HNA-8. markers in all five families and the analysis of informative recombinants allowed us to reduce the HNA region to a $3.5 \mathrm{cM}$ linkage interval.

\section{Materials and Methods}

\section{Family Data}

Five pedigrees were included in our linkage study (Figure 2, Table 1). Genealogical studies and clinical investigations were performed by MW (HNA-1), FS (HNA-2 and HNA-9), EA (HNA-5), AP-S (HNA-8), and JMP (HNA-9). HNA-1 and HNA-2 were previously reported. ${ }^{15,16}$ In this study, additional individuals have been included in pedigree HNA-2, IV-20 and IV-21. HNA was diagnosed according to the following diagnostic criteria: dominant inheritance and single or recurrent episodes of painful brachial plexus neuropathy characterised by muscle weakness and atrophy, followed by full or partial recovery. ${ }^{2}$ Clinical status and ages at onset of deceased individuals were communicated by other family members.

\section{DNA Analysis}

Genomic DNA samples of the HNA patients and their family members were obtained after informed consent. In HNA-1 and HNA-2, genotype analysis was previously performed with four STR markers, the tetranucleotide repeat marker D17S1301 (CHLC.GATA28D11) and the dinucleotide repeat markers D17S939 (AFM267 xh1), D17S802 (AFM210 x a5) and D17S784 (AFM044xg3). ${ }^{15,16}$ In this study, the four STR markers were also screened in families HNA-5, HNA-8 and HNA-9. Furthermore, all five HNA families were genotyped with eight additional STRs located within the $16 \mathrm{cM}$ region defined by Stögbauer et al: ${ }^{16}$ D17S1603 (AFMa135xd5), D17S1817 (AFMa312ya5), D17S801 (AFM203x g5), D17S785 (AFM049 x c1), D17S937 (AFM107ye3), D17S1847 (AFMb310yf5), D17S836 (AFM163yg1) and D17S1806 (AFMa238yb5). The order of the STR markers and their genetic distances are according to the Généthon genetic map $^{17}$ (Figure 1). Genomic DNA (50 ng) was amplified by $\mathrm{PCR}$ in a $25 \mu \mathrm{l}$ reaction volume, containing $10 \mathrm{pmol}$ of each primer and 0.1 U Taq DNA polymerase (Gibco BRL, Rockville, MA, USA). PCR amplification was performed in a thermal cycler (Techne PHC-3, New Brunswick Scientific, The Netherlands). Forward primers were labelled with fluorophores (Applied Biosystems, ABI, Foster City, California, USA). Fragment analysis was performed on $4 \%$ polyacrylamide gels, using an ABI automated DNA sequencer 377 , provided with the ABI GENESCAN software version 2.2 and GENOTYPER version 2.0 .

\section{Linkage Analysis}

Two-point lod scores were computed using the MLINK program of the FASTLINK package. ${ }^{18}$ Multipoint linkage studies were performed with the VITESSE algorithm. ${ }^{19}$ The calculations assumed autosomal dominant inheritance, a disease frequency of $1 / 10000$, phenocopy frequency at $0.0 \%$ and equal male and female recombination rates. Allele 
frequencies of the STR markers were obtained from the Genome Data Base (http://gdbwww.gdb.org). Based on the distribution of the ages at onset in all families (Table 1 ), seven age-dependent penetrance classes were computed. The overall penetrance in the oldest age class (over 40 years of age) was estimated at 0.95 using the ILINK programme. ${ }^{20}$

\section{Results}

This linkage study comprised five families, of which one was previously reported to be linked to chromosome $17 \mathrm{q} 25 .{ }^{16}$ Another family showed suggestive linkage to

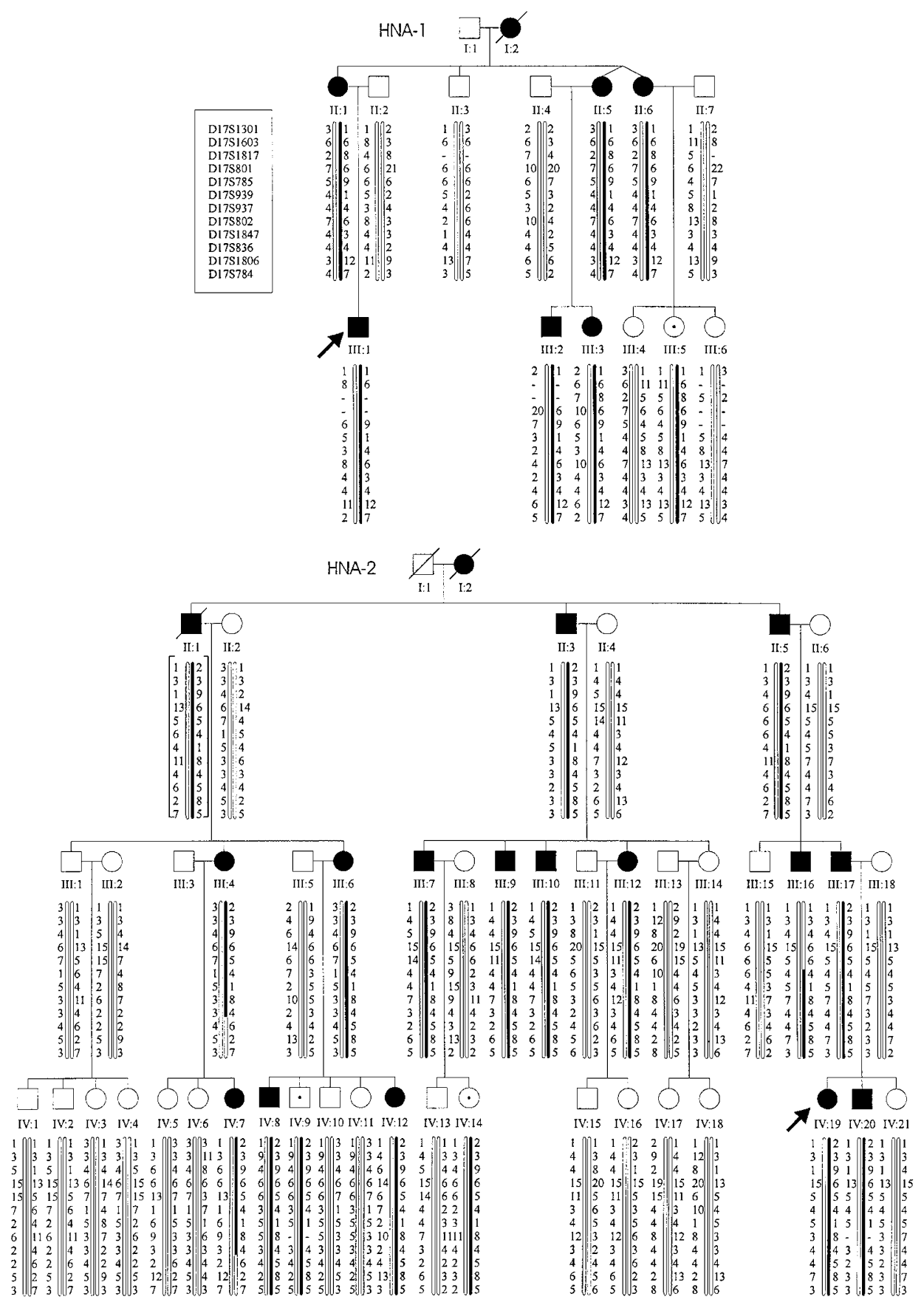

Figure $2 H N A$ pedigrees $H N A-1, H N A-2, H N A-5, H N A-8, H N A-9$, and segregation analysis. Filled symbols: affected; empty: healthy; dot: carrier; slash: deceased; arrow: proband. Genotypes are shown next to the vertical bars; filled bar: disease haplotype; in parentheses: inferred haplotypes; parentheses: genotypes of which phase could not be determined. The analysed STR markers are shown in the box to left of pedigree HNA-1. The haplotypes were constructed in accordance with published genetic marker distances. $^{17}$ 

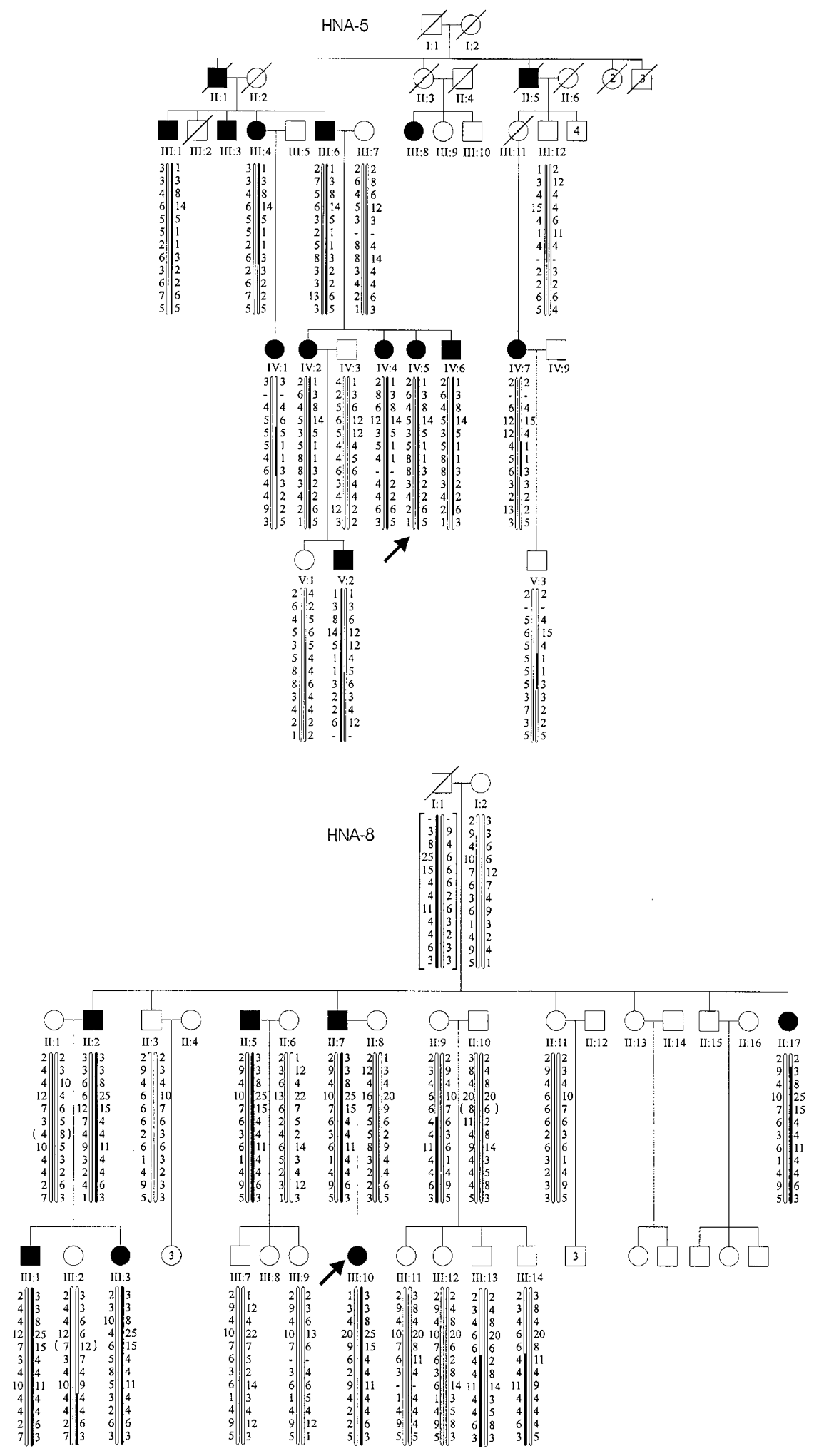

Figure 2 Continued 


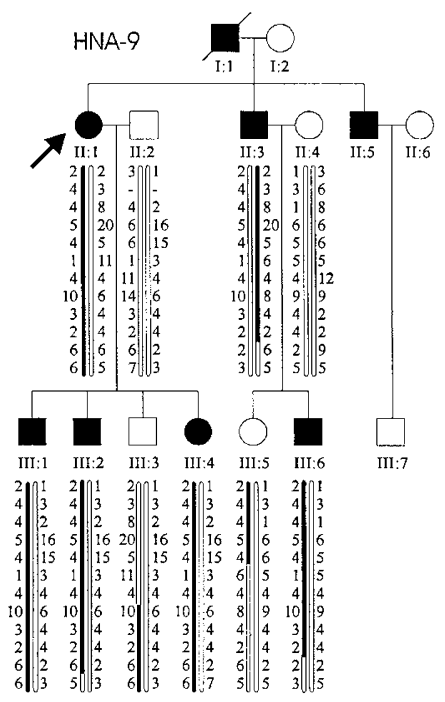

Figure 2 Continued

the same region. ${ }^{15}$ The pedigrees and haplotype analysis of STR markers are depicted in Figure 2. To improve the accuracy of linkage calculations, we studied the penetrance of HNA in these families. The mean ages at onset and their standard deviations are shown in Table 1. Based on the age at onset curve, we defined seven age-dependent penetrance classes. For each of these penetrance classes, we computed the mean penetrance using the ILINK programme (0-4 years: $0.077,5-9$ years: $0.19,10-14$ years: $0.39,15-19$ years: $0.62,20-24$ years: $0.79,25-39$ years: 0.91 , and older than 40 years: 0.95 ).

In order to refine the HNA region, we performed a genetic linkage study using 12STR markers from within the $16 \mathrm{cM}$ linkage interval reported by Stögbauer et $a l,{ }^{16}$ as shown in Figure 1 . This region comprises the $4 \mathrm{cM}$ region reported by Pellegrino et al. ${ }^{14}$ The genotypes and the segregation of the disease haplotype in each of these families are shown in Figure 2. The twopoint linkage results are summarised in Table 2.

Conclusive linkage with one or more polymorphic markers was detected in families HNA-2, HNA-5 and HNA-8. In HNA-2, a disease haplotype segregated in all patients and in two asymptomatic individuals (IV-9 and IV-14), currently 3 and 7 years old. Two informative recombinants were found in affected individuals III-16 and III-4. Patient III-16 has a crossing-over between D17S785 and D17S939, reducing the candidate region at the centromeric side. The crossing-over between D17S1847 and D17S836 in patient III-4 reduces the linkage interval at the telomeric side. Together, the two informative recombinants refined the $16 \mathrm{cM}$ region to a
$9.3 \mathrm{cM}$ region between D17S785 and D17S836 (Figure 1, HNA-1). In family HNA-5, a disease haplotype segregated in all patients and recombinations were found in the affected individuals III-4, IV-1 and IV-7. Patient III-4 had a crossing-over between D17S802 and D17S1847. Patient IV-1 had a crossing-over between D17S801/D17S785 and D17S939. Since the deceased individual III-11 was clinically unaffected whereas her daughter (IV-7) is affected, either the mother (III-11) was an obligate carrier or the daughter (IV-7) represents a phenocopy. However, since the affected daughter (IV-7) has part of the disease haplotype (1-1-3 for D17S939-D17S937-D17S802), it is more likely that the individual III-11 was an obligate carrier. Also, the crossing-over between D17S785 and D17S939 in patient IV-7 confirms the results found in patient III-16 from family HNA-2. Furthermore, patient IV-7 has a distal crossing-over between D17S802 and D17S1847. In family HNA-5, the son of IV-7 (V-3, currently 21 years old, penetrance class 5) has inherited in part the disease haplotype but so far is clinically unaffected. In family HNA-8, a disease haplotype was segregating with the HNA phenotype in all affected individuals. However, three unaffected persons (II-9 and her two sons III-13 and III-14) carry part of the common disease haplotype (4-4-11-4-4-6-3 for the loci D17S939-D17S937-D17S802-D17S1847-D17S836-

D17S1806-D17S784). The current age of these individuals is 49,22 and 18 years, respectively. With a disease penetrance in the oldest age class ( $>40$ years) of $95 \%$, the individual II-9 in family HNA-8 has a probability of less than $5 \%$ of being a mutation carrier, as calculated using ILINK. Moreover, both children (III-13 and III14), who inherited part of the disease haplotype, exceed the mean age at onset in this family without being affected (Table 1). Therefore, this recombination event in an unaffected at risk individual most likely reduces the HNA linkage interval to $2.2 \mathrm{cM}$ (Figure 1, region B) between the STR markers D17S785 and D17S939/D17S937 (which are unordered on the genetic map $^{17}$ ). A multipoint linkage analysis was performed in HNA-8 with the markers D17S1301-D17S785D17S939-D17S802, with D17S1301 placed at 0 cM. A maximum lod score of 3.19 was obtained at D17S785 with a $95 \%$ confidence interval of $4 \mathrm{cM}$, between D17S1301 and D17S939 (data not shown).

Positive, but non-conclusive lod scores were obtained in families HNA-1 and HNA-9, suggesting linkage to the HNA locus on chromosome 17q25. These lod scores were the highest that can be obtained in these families. 
Table 1 Mean age at onset with standard deviations (SD) and geographic origin of the five HNA families

\begin{tabular}{|c|c|c|c|c|c|c|}
\hline Family & Origin & No. individuals & No. affected & $\begin{array}{l}\text { Mean age at } \\
\text { onset (year) }\end{array}$ & $\begin{array}{l}S D \\
\text { (year) }\end{array}$ & Reference \\
\hline HNA-1 & German & 14 & 6 & 14.14 & 11.44 & 15 \\
\hline HNA-2 & Turkish & 44 & 15 & 16.50 & 9.81 & 16 \\
\hline HNA-5 & Finnish & 15 & 10 & 13.30 & 9.03 & 9 \\
\hline HNA-8 & Spanish & 22 & 7 & 15.00 & 7.59 & \\
\hline HNA-9 & Spanish & 10 & 6 & 11.00 & 6.48 & 22 \\
\hline
\end{tabular}

In family HNA-1, a disease haplotype segregated in all patients and in one asymptomatic individual (III-5), as previously reported. ${ }^{15}$ No informative recombinations were found in this family. In all patients of family HNA9, a disease haplotype segregated and no recombination event that would further refine the HNA region occurred. However, two unaffected individuals (III-3 and III-5) carried part of the disease haplotype: 10-3-2-6-6 for the markers D17S802-D17S1847D17S836-D17S1806-D17S784 and 2-4-4-5-4 for the markers D17S1301-D17S1603-D17S1817-D17S801D17S785, respectively.

\section{Discussion}

In this study, non-penetrance of HNA was observed in one person (III-11 in HNA-5). Since disease penetrance has not yet been reported for HNA, we calculated the age-penetrance curve, based on the ages at onset in the five HNA families studied. Seven age-dependent penetrance classes were used to obtain more accurate linkage results. The use of detailed age-penetrance classes, explains the small differences in the lod scores obtained in this study compared with those calculated for some STR markers in families HNA-1 and HNA-2, in our previous study, ${ }^{15,16}$ but the significance of the linkage results has not changed.

The linkage results in the five HNA families studied confirm the previously reported HNA locus on chromosome $17 q .{ }^{13}$ It is of interest that linkage to this $17 q 25$ locus was observed in families of different geographic origin. However, no common disease haplotype was detected between the families, suggesting that these families are most likely not related and that the HNA phenotype can result from different mutations in the same gene.

Based on informative recombinations in affected individuals in family HNA-2, we were able to refine the $16 \mathrm{cM}$ linkage interval (Figure 1, Stögbauer et al ${ }^{16}$ ) to a $9.3 \mathrm{cM}$ region between the STR markers D17S785 and D17S836 (Figure 1, HNA-2). Two crossing-over events in patients belonging to different families (HNA-2 and HNA-5) define the centromeric flanking marker D17S785. In HNA-5, the recombinations in patients III-4, IV-1 and IV-7 define a $7.6 \mathrm{cM}$ region between D17S785 and D17S1847 (Figure 1, HNA-5). Overlap between the $9.3 \mathrm{cM}$ linkage interval (Figure 1, HNA-1), the $7.6 \mathrm{cM}$ region (Figure $1, \mathrm{HNA}-5$ ) and the $4 \mathrm{cM}$ region previously reported by Pellegrino et $a l^{14}$ (Figure 1) defines a HNA region of $3.5 \mathrm{cM}$ between D17S785 and D17S802 (Figure 1, region A). An informative recombination in an unaffected individual in family HNA-8, further reduces the HNA linkage interval with a high probability to a $2.2 \mathrm{cM}$ region between the STR markers D17S785 and D17S939, (Figure 1, region B). Further refinement was not possible due to the lack of additional STR markers between D17S785 and D17S939.

The construction of a physical map of the region containing the HNA locus will enable us to assign candidate genes and expressed sequence tags, and eventually identify additional genes by cDNA selection and exon-trapping. We have recently excluded two positional and functional candidate genes: a putative sialyltransferase and the SFRS2 splicing factor. ${ }^{21}$ The choice of relevant functional candidate genes is very difficult, because nearly nothing is known about the pathogenesis of HNA. Therefore every candidate gene mapping to the HNA locus should be considered a potential HNA gene.

\section{Acknowledgements}

We are grateful to the patients and their relatives for their kind cooperation in our research project and to Dr $\mathrm{P}$ Raeymaekers for helpful discussions. This work was in part funded by a grant of the Fund for Scientific Research, Flanders (FWO), Belgium; the Association Française contre les Myopathies (AFM); and the Kommission Innovative Medizinische Forschung (IMF) of the University of Münster, Germany (St-1-1-I/97-7). JM is supported by a fellowship from the Institute for Science and Technology (IWT), Belgium (IWT-961076). GK received a postdoctoral fellowship from the Deutsche Forschungsgemeinschaft (DFG, KU 
Table 2 Two-point lod scores obtained in the five HNA families with 12 chromosome 17q25 STR markers

\begin{tabular}{|c|c|c|c|c|c|c|c|c|}
\hline \multirow[b]{2}{*}{ Marker } & \multirow[b]{2}{*}{ Family } & \multicolumn{7}{|c|}{ Lod scores $(Z)$ at recombination fractions $(\theta)$} \\
\hline & & 0 & 0.01 & 0.05 & 0.1 & 0.2 & 0.3 & 0.4 \\
\hline \multirow[t]{5}{*}{ D17S1301 } & HNA-1 & 0.44 & 0.44 & 0.42 & 0.38 & 0.27 & 0.14 & 0.04 \\
\hline & HNA-2 & -0.32 & 3.21 & 3.56 & 3.42 & 2.78 & 1.91 & 0.90 \\
\hline & HNA-5 & -4.84 & -1.32 & -0.12 & 0.27 & 0.43 & 0.34 & 0.16 \\
\hline & HNA-8 & -6.91 & -0.19 & 0.36 & 0.48 & 0.40 & 0.21 & 0.05 \\
\hline & HNA-9 & 0.20 & 0.20 & 0.17 & 0.14 & 0.08 & 0.04 & 0.01 \\
\hline \multirow[t]{4}{*}{ D17S1603 } & HNA-1 & -0.17 & -0.15 & -0.09 & -0.05 & 0.00 & 0.01 & 0.00 \\
\hline & HNA-5 & 1.70 & 1.67 & 1.54 & 1.37 & 1.02 & 0.64 & 0.27 \\
\hline & HNA-8 & 0.65 & 0.64 & 0.60 & 0.54 & 0.42 & 0.29 & 0.15 \\
\hline & HNA-9 & 1.01 & 0.99 & 0.90 & 0.79 & 0.55 & 0.30 & 0.09 \\
\hline \multirow[t]{5}{*}{ D17S1817 } & HNA-1 & 0.44 & 0.43 & 0.38 & 0.33 & 0.21 & 0.11 & 0.03 \\
\hline & HNA-2 & 0.20 & 3.45 & 3.80 & 3.64 & 2.94 & 2.01 & 0.94 \\
\hline & HNA-5 & -2.72 & -0.43 & 0.36 & 0.63 & 0.65 & 0.44 & 0.18 \\
\hline & HNA- 8 & 3.19 & 3.14 & 2.92 & 2.64 & 2.04 & 1.36 & 0.61 \\
\hline & HNA-9 & 1.01 & 0.99 & 0.91 & 0.81 & 0.58 & 0.33 & 0.11 \\
\hline \multirow{4}{*}{ D17S801 } & HNA-2 & 3.32 & 3.26 & 3.02 & 2.72 & 2.05 & 1.33 & 0.55 \\
\hline & HNA-5 & -1.52 & 0.80 & 1.31 & 1.37 & 1.14 & 0.75 & 0.32 \\
\hline & HNA-8 & 3.19 & 3.14 & 2.92 & 2.64 & 2.04 & 1.36 & 0.61 \\
\hline & HNA-9 & 1.13 & 1.11 & 1.02 & 0.90 & 0.64 & 0.37 & 0.12 \\
\hline \multirow[t]{5}{*}{ D17S785 } & HNA-1 & 1.44 & 1.42 & 1.30 & 1.16 & 0.83 & 0.47 & 0.14 \\
\hline & HNA-2 & -2.95 & 0.20 & 0.76 & 0.88 & 0.81 & 0.61 & 0.34 \\
\hline & HNA-5 & -0.74 & 0.85 & 1.34 & 1.39 & 1.16 & 0.76 & 0.33 \\
\hline & HNA-8 & 3.19 & 3.14 & 2.92 & 2.64 & 2.04 & 1.36 & 0.61 \\
\hline & HNA-9 & 1.10 & 1.08 & 0.99 & 0.88 & 0.62 & 0.36 & 0.11 \\
\hline \multirow[t]{5}{*}{ D17S939 } & HNA-1 & 1.49 & 1.46 & 1.34 & 1.19 & 0.85 & 0.48 & 0.15 \\
\hline & HNA-2 & 3.26 & 3.21 & 2.97 & 2.66 & 2.00 & 1.29 & 0.57 \\
\hline & HNA-5 & 2.81 & 2.80 & 2.71 & 2.52 & 2.01 & 1.38 & 0.69 \\
\hline & HNA- 8 & 0.18 & 0.91 & 1.37 & 1.43 & 1.24 & 0.86 & 0.40 \\
\hline & HNA-9 & 1.58 & 1.55 & 1.41 & 1.25 & 0.89 & 0.52 & 0.17 \\
\hline \multirow[t]{3}{*}{ D17S937 } & HNA-1 & 0.63 & 0.61 & 0.55 & 0.48 & 0.32 & 0.17 & 0.05 \\
\hline & HNA-2 & 5.26 & 5.18 & 4.83 & 4.37 & 3.38 & 2.27 & 1.05 \\
\hline & HNA-9 & 0.17 & 0.17 & 0.15 & 0.12 & 0.07 & 0.03 & 0.01 \\
\hline \multirow[t]{5}{*}{ D17S802 } & HNA-1 & 0.63 & 0.62 & 0.59 & 0.54 & 0.40 & 0.24 & 0.09 \\
\hline & HNA-2 & 5.20 & 5.12 & 4.76 & 4.30 & 3.30 & 2.21 & 1.02 \\
\hline & HNA-5 & 3.07 & 3.01 & 2.78 & 2.49 & 1.87 & 1.20 & 0.54 \\
\hline & HNA-8 & 0.29 & 1.19 & 1.66 & 1.70 & 1.44 & 1.00 & 0.47 \\
\hline & HNA-9 & 0.84 & 0.83 & 0.77 & 0.69 & 0.49 & 0.27 & 0.08 \\
\hline \multirow[t]{5}{*}{ D17S1847 } & HNA-1 & 1.18 & 1.16 & 1.07 & 0.94 & 0.65 & 0.34 & 0.09 \\
\hline & HNA-2 & 2.69 & 2.65 & 2.46 & 2.21 & 1.67 & 1.08 & 0.48 \\
\hline & HNA-5 & -2.73 & -0.82 & -0.01 & 0.30 & 0.43 & 0.34 & 0.17 \\
\hline & HNA- 8 & -0.22 & 0.51 & 1.01 & 1.12 & 1.00 & 0.70 & 0.31 \\
\hline & HNA-9 & 0.31 & 0.30 & 0.26 & 0.21 & 0.12 & 0.06 & 0.01 \\
\hline \multirow[t]{5}{*}{ D17S836 } & HNA-1 & -0.16 & -0.14 & -0.09 & -0.04 & 0.00 & 0.00 & 0.00 \\
\hline & HNA-2 & -2.93 & 3.03 & 3.41 & 3.29 & 2.68 & 1.84 & 0.86 \\
\hline & HNA-5 & 2.23 & 2.23 & 2.17 & 2.02 & 1.60 & 1.09 & 0.54 \\
\hline & HNA-8 & -0.04 & -0.04 & -0.02 & -0.01 & 0.02 & 0.03 & 0.03 \\
\hline & HNA-9 & -0.01 & -0.01 & -0.01 & -0.01 & 0.00 & 0.00 & 0.00 \\
\hline \multirow[t]{5}{*}{ D17S1806 } & HNA-1 & 1.49 & 1.46 & 1.34 & 1.19 & 0.85 & 0.48 & 0.15 \\
\hline & HNA-2 & -2.95 & 3.01 & 3.39 & 3.28 & 2.67 & 1.84 & 0.85 \\
\hline & HNA-5 & -2.16 & -0.70 & 0.46 & 0.78 & 0.79 & 0.51 & 0.15 \\
\hline & HNA-8 & 0.08 & 0.81 & 1.29 & 1.37 & 1.20 & 0.84 & 0.39 \\
\hline & HNA-9 & -3.51 & -1.19 & -0.53 & -0.28 & -0.09 & -0.02 & 0.00 \\
\hline D17S784 & HNA-1 & 1.49 & 1.46 & 1.34 & 1.19 & 0.85 & 0.48 & 0.15 \\
\hline & HNA-2 & -3.81 & 2.16 & 2.59 & 2.54 & 2.08 & 1.41 & 0.63 \\
\hline & HNA-5 & -3.23 & -0.11 & 0.44 & 0.55 & 0.48 & 0.31 & 0.14 \\
\hline & HNA-8 & 0.68 & 0.67 & 0.64 & 0.59 & 0.49 & 0.35 & 0.19 \\
\hline & HNA-9 & -8.08 & -2.89 & -1.49 & -0.90 & -0.37 & -0.13 & -0.03 \\
\hline
\end{tabular}


1194/1-1). VT is a postdoctoral fellow of the FWO, Belgium. CVB is the coordinator of the European CMT consortium sponsored by European Union BIOMED2 grants (CT961614 and CT960055). JM and GK contributed equally to this work.

\section{References}

1 Online Mendelian Inheritance in Man, OMIM (TM). John Hopkins University, Baltimore, MD. MIM Number: \{162100\}: \{3/13/1998\}. World Wide Web URL: http:/ /www.ncbi.nlm.nih.gov/omim/

2 Windebank AJ: Inherited recurrent focal neuropathies. In: Dyck PJ, Thomas PK, Griffin JW et al. Peripheral Neuropathy, 3rd edn. Saunders: Phildelphia, 1993, pp 1137-1148.

3 Taylor RA: Heredofamilial mononeuritis multiplex with brachial predilection. Brain 1960; 3: 113-137.

4 Tsairis P, Dyck PJ, Mulder DW: Natural history of brachial plexus neuropathy. Report on 99 patients. Arch Neurol 1972; 27: 109-117.

5 Ungley CC: Recurrent polyneuritis in pregnancy and the puerperium affecting 3 members of a family. $J$ Neurol Psychopathol 1933; 14: 15-26.

6 Geiger LR, Mancall EL, Penn AS et al: Familial neuralgic amyotrophy. Report of three families with review of the literature. Brain 1974; 97: 87-102.

7 Jacob J, Andermann F, Robb J: Heredofamilial neuritis with brachial predilection. Neurology 1961; 11(12): 1025-1033.

8 Gardner JH, Maloney W: Hereditary brachial and cranial neuritis genetically linked with ocular hypotelorism and syndactyly. Neurology 1968; 18: 278.

9 Airaksinen EM, Iivanainen M, Karli P et al: Hereditary recurrent brachial plexus neuropathy with dysmorphic features. Acta Neurol Scand 1985; 71: 309-316.

10 Parsonage MJ, Turner JWA: Neuralgic amyotrophy: shoulder-girdle syndrome. Lancet 1948; 1: 973.

11 Beghi E, Kurland LT, Mulder DW et al: Brachial plexus neuropathy in the population of Rochester, Minnesota, 1970-1981. Ann Neurol 1985; 18: 320-323.
12 Russell JW, Windebank AJ: Brachial and lumbar neuropathies. Baillières Clin Neurol 1994; 3: 173-191.

13 Pellegrino JE, Rebbeck TR, Brown MJ et al: Mapping of hereditary neuralgic amyotrophy (familial brachial plexus neuropathy) to distal chromosome 17q. Neurology 1996; 46: $1128-1132$.

14 Pellegrino JE, George RA, Biegel J et al: Hereditary neuralgic amyotrophy: evidence for genetic homogeneity and mapping to chromosome 17q25. Hum Genet 1997; 101: 277-283.

15 Wehnert M, Timmerman V, Spoelders $\mathrm{P}$ et al: Further evidence supporting linkage of hereditary neuralgic amyotrophy to chromosome 17q. Neurology 1997; 48: $1719-1721$.

16 Stögbauer F, Young P, Timmerman V et al: Refinement of the hereditary neuralgic amyotrophy (HNA) locus to chromosome 17q24-q25. Hum Genet 1997; 99: 685-687.

17 Dib C, Faure S, Fizames C et al: A comprehensive genetic map of the human genome based on 5,264 microsatellites [see comments]. Nature 1996; 380: 152-154.

18 Cottingham RW Jr, Idury RM, Schaffer AA: Faster sequential genetic linkage computations. Am J Hum Genet 1993; 53: 252-263.

19 O'Connell JR, Weeks DE: The Vitesse algorithm for rapid exact multilocus linkage analysis via genotype set-recording and fuzzy inheritance. Nat Genet 1995; 11: 402-408.

20 Lathrop GM, Lalouel J-M: Easy calculation of lod scores and genetic risk on small computers. Am J Hum Genet 1984; 36: 460-465.

21 Kuhlenbäumer G, Meuleman J, Schirmacher A et al: Mutation analysis of a putative sialyltransferase gene, the SFRS2 splicing factor gene and the $c-m y b$ ET-locus in two families with hereditary neuralgic amyotrophy (HNA). Ann Hum Genet 1998; 62: 397-400.

22 Zuazo Zamalloa E, Pomposo Bolumburu I, Garaizar Axpe C et al: Recurrent familial amyotrophic neuralgia of the brachial plexus. Report of a family and review of the literature. An Esp Pediatr 1992; 37: 47-51. 